\title{
LA FORMACIÓN DE LOS JÓVENES EN LIDERAZGO AMBIENTAL COMO UN FACTOR DE APROPIACIÓN TERRITORIAL: EL CASO DE LA INSTITUCIÓN EDUCATIVA DISTRITAL EDUARDO UMAÑA MENDOZA (BOGOTÁ, COLOMBIA)*
}

\author{
Lida Esperanza Carrillo García**
}

\section{Resumen}

Este artículo analiza la manera como se estructuran los procesos de formación del liderazgo en la educación ambiental escolar, y cómo estas habilidades pueden llegar a ser determinantes en la percepción y apropiación territorial de los/as jóvenes, a partir del estudio de caso de la Institución Educativa Distrital Eduardo Umaña Mendoza de Bogotá (IED.EUM). El artículo revisa las disposiciones normativas de la educación ambiental escolar en Colombia, analiza las dinámicas de la educación ambiental que se han desarrollado en dicha institución y reflexiona sobre los procesos de apropiación territorial de los jóvenes líderes ambientales.

Como participantes de esta investigación se contó con cuatro docentes y ochenta estudiantes pertenecientes a la institución educativa seleccionada ${ }^{1}$; junto con tres jóvenes líderes comunitarios vinculados al proyecto escolar. El diseño metodológico incluyó la aplicación de tres entrevistas, una encuesta semiestructurada y la revisión documental institucional como instrumentos para la construcción de información; como técnicas de análisis se recurrió al análisis estadístico, documental y de contenido.

El análisis de los instrumentos permitió develar relaciones entre los procesos de formación en liderazgo desde la escuela y las maneras en que los/as jóvenes perciben su territorio y actúan frente a problemáticas ambientales. La escasa formación en liderazgo ambiental, incide en la indiferencia que los estudiantes manifiestan por su territorio. Es así que el entorno territorial define al líder ambiental y la escuela debe involucrarse en mayor medida en su proceso de formación y contemplar factores como la cultura y la identidad territorial, y dotar a los estudiantes de conocimientos contextuales, así como incentivar su sentido de pertenencia y promover acciones de formación en liderazgo ambiental.

Palabras claves: Ambiente; educación; liderazgo; participación; territorialidad.

\footnotetext{
*Agradecimientos a los organizadores y participantes del $10^{\circ}$ Congreso Internacional de Estudios Ambientales y del Territorio. "Territorios, Espacios Naturales, Sustentabilidad y Crisis de Civilización” (Galápagos Ecuador, junio de 2016) https://www.flacso.edu.ec/portal/contenido/eventos/10-congreso-internacionalbrestudios-ambientales-y-delterritorio.1519, al igual que al "Seminario Internacional de Planeación participativa en América Latina y Colombia" (Bogotá Colombia, Septiembre de 2016) http://aciur.net/noticias-y-eventos/item/seminario-internacional-planeacionparticipativa-y-territorial-en-america-latina-y-colombia, por sus comentarios y aportes, los cuales contribuyeron a fortalecer los ejes de análisis de esta investigación.

${ }^{* * *}$ lidaescg@gmail.com. El presente artículo científico surge como resultado del proceso de investigación realizado para optar el título de Magister en Planeación para el Desarrollo de la Universidad Santo Tomás de Bogotá y contó con la asesoría de la Dra. Angie Carolina Torres Ruiz, docente de dicha maestría. http://scienti.colciencias.gov.co:8081/cvlac/visualizador/generarCurriculoCv.do?cod_rh=0000482552\#

${ }^{1}$ La selección de esta institución se debe a la relación laboral que posee la autora del artículo como investigadora y docente, sumado al proceso que durante 6 años ha acompañado en la construcción de un proyecto ambiental escolar que responda a las necesidades propias del contexto territorial en mención.
} 


\begin{abstract}
Environmental education is paramount in school curriculum frameworks, however, their methods and component required. It is interesting to analyze how development processes such as leadership skills and the impact of it in the forms of land ownership is structured.

The study population ismade up of teachers and students from the School Environmental Committee (CAE), 2013-2015, the District School Eduardo Umaña Mendoza of Bogota. The qualitative research is a descriptive perspective. After validation of tools (interviews, semi-structured survey and focus groups), the work field, accompanied by documentary CAE analysis was performed.
\end{abstract}

Analysis instruments allowed revealing relationships between processes of leadership training from school and the ways in which young people perceive their territory and act against environmental problems. Poor training in environmental leadership in school, makes students and graduates manifest disregard for its territory.

Young people are looking for opportunities for social convergence, there is a synergy between the terms youth and participation. The local environment defines the profile of the environmental leader, the school should be involved more in the process of formation. The training of environmental leaders, requires consideration of factors such as culture and territorial identity; characterize the subject type you want and the profile of the environmental leader is needed; endow knowledge, senses and actions that may be characteristic of a leader.

Keywords: Environment; leadership; education; participation; territoriality.

\title{
Introducción
}

La educación ambiental es un componente considerado como primordial en las estructuras curriculares escolares en Colombia. Al respecto, la Política Nacional de Educación Ambiental plantea: "La escuela debe abrir espacios para este tipo de formación. Debe dar prioridad a la construcción permanente de actitudes y valores sobre la transmisión de productos o resultados del trabajo disciplinario" (Ministerio de Ambiente. 2002, p. 10). Sin embargo, en los documentos de política no se precisan sus métodos, componentes y alcances; y la información acerca de cómo a partir de este ámbito el educando asume o podría asumir una postura frente a su realidad, y actuar en su territorio, es limitada. Resulta entonces pertinente analizar la manera como se estructuran los procesos de educación ambiental en la escuela y establecer si son determinantes de la percepción y apropiación territorial de los/as jóvenes. Para ello, se considera necesario estudiar la relación entre educación y gestión ambiental, desde la perspectiva de la formación del liderazgo ambiental juvenil en el contexto escolar.

La gestión ambiental requiere de la educación ambiental, sin embargo, tiende a desconocerse esta interdependencia en el sistema educativo formal en el que las acciones pedagógicas escolares suelen limitarse a la conceptualización ambiental, sin considerar el contexto territorial en el que se desenvuelve el estudiante (Castrillón \& García, 2009). Según Freire (2002), esta desarticulación entre formación ambiental, acción y contexto, descuida la relacionalidad de los procesos pedagógicos con el mundo próximo. Ante ello, la educación y gestión ambiental deben adquirir una identidad contextual y relacional para dar respuestas claras y asertivas a las problemáticas que se enfrenta. Es así que se puede afirmar que toda actividad, programa o proyecto de educación ambiental debe incorporar un componente de gestión y formación del liderazgo ambiental, donde los participantes amplíen sus capacidades para estructurar, 
implementar y evaluar las estrategias de acción y así, apropiar y construir marcos referenciales a nivel conceptual y operativo, de modo que puedan interactuar e intervenir su contexto social y natural de forma pertinente. (Castrillón \& García, 2009)

Estas son las relaciones que estudia este proyecto de investigación, inscrito en la línea Desarrollo, Políticas Públicas y Planeación Participativa ${ }^{1}$, revisa el marco de la política de educación ambiental en Colombia, analiza la experiencia de formación ambiental desarrollada en la Institución Educativa Distrital Eduardo Umaña Mendoza (IED.EUM) de Bogotá, D.C., y brinda elementos de reflexión que pueden contribuir a emprender o mejorar procesos de planeación participativa de los proyectos de educación ambiental en el caso de estudio, y en otras instituciones escolares.

Así, el artículo se estructura en dos secciones; la primera expone los resultados de la investigación respecto a las iniciativas de formación en liderazgo ambiental juvenil desarrolladas en la IED.EUM entre los años 2007 a 2016, su historia, evolución y la percepción que tienen los estudiantes sobre su participación en éstas y, la segunda, se dedica al análisis de los procesos y factores de apropiación territorial de estudiantes participantes y otros jóvenes líderes ambientales.

\section{Discusión de conceptos claves}

\section{La formación del liderazgo ambiental}

La emocionalidad y las habilidades sociales son características propias de los sujetos (Riggio \& Reichard, 2008) y constituyen una potencialidad pedagógica que debe ser apropiada por las instituciones educativas. El enseñar a los estudiantes a controlar y encaminar las emociones es actualmente un asunto prioritario en las agendas institucionales, pues promete grandes posibilidades en el momento de dar respuesta a muchas de las demandas sociales que se le plantean a la escuela. (Secretaria de Educación de Bogotá. 2012-2)

Así como lo plantean Salovey \& Mayer (1990), Goleman (1995), la capacidad de los estudiantes para identificar y gestionar de manera adecuada sus estados emocionales, les permite entender y controlar sus impulsos, facilitando las relaciones comunicativas con los demás (Riggio \& Reichard, 2008). La comunicación asertiva y el respeto de los derechos del otro, de esta manera, se vuelven determinantes, por ser habilidades propias de los líderes. (Secretaría de Educación de Bogotá, 2012-2)

En el contexto escolar, estamos en condiciones académicas ${ }^{2}$ para introducir en el diseño de planes formativos, prácticas que fomenten la empatía, el liderazgo y la inteligencia emocional, (Posner \& Kouzes, 1997, Zárate \& Matviuk, 2012, Goleman, 1999). Así lo plantea el documento base en desarrollo socio afectivo presentado por la Secretaria de Educación de Bogotá (2012-2), que estructura de manera general los componentes que deben guiar las prácticas pedagógicas hacia el desarrollo de habilidades emocionales.

\footnotetext{
${ }^{1}$ Esta línea de investigación nutre varios de los espacios académicos de la Maestría en Planeación para el Desarrollo así como del pregrado de la Facultad de Sociología de la Universidad Santo Tomas de Colombia, fortalece espacios académicos como: Teorías y perspectivas del desarrollo humano integral, Modelos y tendencias del Desarrollo en América Latina y en Colombia, políticas públicas, entre otros. Universidad Santo Tomas. USTA. (2014).

${ }^{2}$ Conocimiento disponible sobre los mecanismos del sistema emocional.
} 
Es así que la escuela debe propender por la formación de líderes transformacionales, es decir, por personas emprendedoras, visionarias, con habilidad para inspirar (Barbuto \& Burbach, 2006, Bass \& Riggio, 2006, Zárate \& Matviuk, 2012), dispuestos a escuchar, a reconocer sus emociones, creencias y valores, a potenciar sus acciones y productos a través de la participación en la organización (Pascagaza \& Javier 2010). Una de sus principales actitudes debe ser la disposición a ayudar a las comunidades a clarificar sus metas, dilucidar la complejidad de los acontecimientos y de las interacciones sociales, seleccionar alternativas prácticas y proponer proyectos futuros (Zárate \& Matviuk, 2012).

Estas habilidades y actitudes llevadas al ámbito ambiental se pueden traducir como la capacidad de generar el encuentro, el intercambio de experiencias, la identificación de situaciones ambientales, la circulación de discursos, el reconocimiento de los contextos, la planeación de acciones y la participación comunitaria; siendo éstas algunas de las actividades que deben acompañar la formación de los jóvenes líderes ambientales, usando diferentes espacios, procesos y estrategias (Pascagaza \& Javier 2010). Es así como el Estado colombiano reglamenta la institucionalización de la educación ambiental y la define en su artículo primero como un "proceso dinámico y participativo" (ley1549, 2012, p.1) hacia la formación de personas con actitudes y capacidades particulares para "la construcción de sociedades ambientalmente sustentables y socialmente justas" (ídem, p.1).

\section{Participación y territorialidad de los jóvenes}

En ámbitos académicos, marcos de acción de proyectos gubernamentales, comunitarios y de políticas públicas, los/as jóvenes se han venido situando como actores estratégicos, por lo que se hace necesario caracterizar las formas de configuración de sus identidades, destacando la socialización que, en el mundo tecnológico actual, se modifica y enriquece a cada instante. (Guerrero, 2009). Por lo que resulta urgente en este contexto, la generación de condiciones para el ejercicio de la ciudadanía ${ }^{3}$ en los y las adolescentes como "actores transformadores de su propia realidad" (de Bogotá, A. M., 2011, p.22), dados los profundos cambios en la integración social a nivel familiar, escolar y laboral que han desarticulado las vías tradicionales de participación política. Por ello, en el ámbito académico, el tema de la participación juvenil cobra cada vez más espacio. Los/as jóvenes de hoy encuentran en mecanismos de participación alternativos $^{4}$, la posibilidad de constituir su propio mundo, crean identidades, sensibilidades y expresiones sobre el sistema político en el que están insertos. (Otero, 2003, Ortega, 2012)

En perspectiva, el documento las Políticas públicas de juventudes en América Latina, destaca la inminente necesidad de repensar la escuela como un lugar integrador de las nuevas generaciones de adolescentes, fundamentado en el conocimiento de su realidad y sus ideales (Rodríguez, 2010), para así brindarles herramientas que les permitan conectar de manera más visible para

\footnotetext{
${ }^{3}$ Desde la Política distrital de infancia y adolescencia se contempla que el ejercicio de la ciudadanía, involucra el reconocimiento como actores de sus propios derechos, implica partir de su condición de actores transformadores de su propia realidad tanto en el plano individual como colectivo, siendo necesario crear espacios, facilitar condiciones y construir mecanismos que permitan el pleno ejercicio de la autonomía, la exigencia de su cumplimiento y el rechazo de su vulneración. (de Bogotá, A. M., 2011, p.22)

4 Maffesoli plantea la relevancia de distintas formas de coparticipación comunitaria movida por una actitud sentimental en donde el autorreconocimiento es el móvil básico que preside la lógica de lo social y permite comprender particularidades de la cultura postmoderna. (Pasín, Á. E. C., 2003. p.203).
} 
ellos, las actividades escolares con sus entornos y sus procesos de territorialidad.

Por ello la importancia especial que tiene la geografía y conformación territorial ${ }^{5}$ en la juventud rural y urbano - rural, por el amplio dominio del territorio que pueden alcanzar estos jóvenes. (Guerrero, 2009). Así, "La escuela, más allá de un espacio físico, tiene toda una connotación sociocultural y constituye un espacio de identidad y diferenciación" (Guerrero, 2009 p. 611). La comprensión del territorio para ellos, es el punto de partida para que se den los procesos de territorialidad que sustentarán el desarrollo para sus comunidades (Vidal \& Pol, 2005). Entonces, es urgente resignificar la dimensión territorial de los conceptos ambientales, dejar de observar los conflictos ambientales como meras reivindicaciones económicas e incorporar los elementos identitarios y territoriales en sus análisis, como elementos esenciales de la pedagogía ambiental (Leff, 2002).

En este contexto, es indispensable entender el territorio, reconociendo su conflictividad, y fundar su análisis en el tejido de memorias colectivas, para desde allí estructurar propuestas de reconfiguración territorial, hechas desde una perspectiva cultural, con énfasis en aspectos no siempre lo suficientemente abordados, como la intersubjetividad, el conflicto, la complejidad y la inestabilidad (Lozano, 2012). El concepto del lugar también permite acercarnos a la comprensión de la cultura, el conocimiento, la naturaleza, y la economía, pero requiere recobrar su valor desdibujado a partir de los procesos de globalización (Escobar, 2000). Por ello, la urgente necesidad de reafirmar la identidad cultural como manifestación de lo real y lo verdadero, en donde el territorio se consolide como el lugar donde la sustentabilidad se enraíza en bases ecológicas e identidades culturales (Leff 2002).

Desde esta óptica, la apropiación territorial es punto clave en "el abordaje de cuestiones como la construcción social del espacio público, la ciudadanía, la sostenibilidad (ambiental, económica y social) y en suma para aportar elementos teóricos y empíricos que permitan investigar e intervenir modos de interacción social más eficaces, justos y adecuados a las demandas sociales actuales." (Vidal, y Pol, 2005, p.1)

Esta perspectiva territorial dentro de los procesos de educación ambiental escolar, requiere de la formación de gestores juveniles influyentes dentro de sus comunidades, por ello resulta conveniente revisar la política ambiental y las posibilidades que ésta brinda a dichos procesos formativos desde la escuela.

\section{Una mirada a la política nacional y distrital para la educación ambiental.}

El Estado colombiano, a partir de la Constitución política de 1991 ha venido desarrollando una propuesta nacional de educación ambiental, cuya inclusión temática en los entornos educativos se planteó como objetivo primordial en la Ley General de Educación (Ley 115 de 1994). Así, la educación ambiental se contempla como una estrategia importante de las políticas públicas nacionales y locales a partir la reforma educativa nacional, que enmarcó dicha ley. (Colombia. Ministerio de Medio Ambiente y Ministerio de Educación Nacional. [MMA \& MEN], 2002). En el contexto jurídico y legislativo anterior, se desarrollaron avances significativos en lo que tiene que ver con el proceso de institucionalización de la política de educación ambiental en Colombia

\footnotetext{
${ }^{5}$ La conformación de los territorios se delimite en razón del conjunto de prácticas y vínculos de dominio, de poder, de pertenencia o de apropiación que se ejercen sobre espacios geográficos específicos. (Pérez, M. 2004. p.63).
} 
y en el Distrito Capital. A continuación, se presenta una síntesis de los principales referentes normativos.

Tabla 1

La política nacional y distrital para la educación ambiental.

Año Documento Propósitos y/o aportes

1993 Ley 99 de 1993 Se crea el Ministerio de Medio Ambiente y se estructura el Sistema Nacional Ambiental (SINA). Éste representa el "conjunto de orientaciones, normas, actividades, recursos, programas e instituciones que permiten la puesta en marcha de los principios generales ambientales" (Ley 99/93, Art. 4).

1994 Ley 115 de La inclusión de la Educación Ambiental, se consolidó como un elemento 1994 Ley de acción que obliga a las Instituciones Educativas a manejar este General de componente trasversalmente en los currículos escolares.
Educación

1995 Política Ubica el desarrollo sostenible como una de las metas del desarrollo del Nacional país, y a la Educación Ambiental dentro de las estrategias primordiales Ambiental para disminuir el deterioro del ambiente, contribuyendo a las metas de desarrollo. (MMA \& MEN, 2002)

1996 Plan Decenal de Incorpora la educación ambiental como una perspectiva indispensable Educación 1996-2005 para el mejoramiento de la calidad de vida del país, principio base que mantiene el actual Plan Decenal de Educación 2006-2016.

2011 Decreto 675 Reglamenta la Política Pública Distrital de Educación Ambiental. Dentro de sus principios rectores propone una educación diferencial, en donde la diversidad cultural y social propicie el encuentro de saberes, con la participación de diversos actores en torno a los objetivos de la gestión ambiental distrital. Se reglamenta la creación de la Comisión Intersectorial de Educación Ambiental (CIDEA), como instancia articuladora de la gestión de la educación ambiental distrital, encargada de promover estrategias tales como los PRAE $^{6}$, y los Procesos Comunitarios de Educación Ambiental (PROCEDA), entre otros. (Decreto 675, 2011)

2012 Ley 1549 de "Por medio de la cual se fortalece la institucionalización de la política 2012 nacional de educación ambiental y su incorporación efectiva en el desarrollo territorial" (p.1).

Fuente: Recopilación realizada por la autora desde las fuentes oficiales citadas.

\footnotetext{
${ }^{6}$ Los PRAE son proyectos que incorporan la problemática ambiental local al quehacer de las instituciones educativas, teniendo en cuenta su dinámica natural y socio-cultural de contexto. Dicha incorporación tiene el carácter transversal e interdisciplinario propio de las necesidades de la comprensión de la visión sistémica del ambiente y de la formación integral requerida para la comprensión y la participación en la transformación de realidades ambientales locales, regionales y/o nacionales. http://www.colombiaaprende.edu.co/html/mediateca/1607/article-81637.html
} 
A partir de la Constitución Política de Colombia (1991), se brindan oportunidades al trabajo en educación ambiental, al incorporarla dentro de los conceptos de autonomía y descentralización. Así, la ley 99/93 presenta al SINA como una experiencia novedosa en el país en materia de coordinación de actores, alrededor de la gestión ambiental nacional, al integrar los estamentos estatales con la sociedad civil organizada, los diversos grupos étnicos del país y el sector privado y académico (MMA \& MEN, 2002). En este entorno de integración de actores y ya a nivel local, la política distrital de educación ambiental de 2011 presenta una apuesta social estructurada y posiciona de nuevo a las Instituciones educativas con sus PRAE como entes articuladores de actores sociales alrededor de la gestión ambiental.

Esta institucionalización normativa de la educación ambiental presiona a las comunidades educativas a cumplir con los lineamientos legales, pero no orienta, de manera suficiente, las posibilidades de implementación, apropiación y proyección. Las demandas institucionales que deben atender las escuelas y la multiplicidad de lineamientos curriculares frente a los que debe ofrecer respuesta rápida y eficiente, implica, en muchas ocasiones, que los equipos de trabajo de las instituciones escolares se preocupen por cumplir con los estándares y formatos requeridos, sin contar con los tiempos necesarios para planear procesos de forma crítica, con suficiente fundamento académico, contando con la participación de los diferentes actores de la comunidad educativa y en diálogo con el contexto del cual hace parte.

En el caso de la educación ambiental escolar, contar con un marco normativo favorable es importante, pero no suficiente y, por ello, esta investigación pretende aportar elementos críticos para la revisión de las iniciativas desarrolladas en el colegio Eduardo Umaña Mendoza y posibilitar la incorporación de estas experiencias en instituciones educativas con características similares.

\section{Contexto de investigación}

La Institución Educativa Distrital Eduardo Umaña Mendoza ${ }^{7}$ (IED.EUM) fue fundada en el año 2005; está ubicada al costado sur oriental de la ciudad de Bogotá, D.C., más específicamente, en el Barrio Villa Alemana de la localidad de Usme ${ }^{8}$. Se encuentra en una de las áreas de transición entre la zona urbana y la rural; cuenta con ecosistemas estratégicos y espacios integrales de la estructura ecológica principal de la ciudad, es punto de conexión con la región de los Llanos Orientales y colinda con áreas de protección ambiental (Parque Entre Nubes y Páramo Sumapaz). (IED Eduardo Umaña Mendoza, 2010)

\footnotetext{
${ }^{7}$ Recibe su nombre en homenaje al reconocido abogado Eduardo Umaña Mendoza, asesinado por su compromiso con los sectores populares de Colombia y la defensa de los Derechos Humanos. (Secretaria de Educación Distrital. 2014).

${ }^{8}$ La ciudad de Bogotá está dividida en veinte (20) unidades de administración local denominadas localidades. La jurisdicción de la localidad Quinta de Usme, se extiende en tres de los territorios ambientales de la ciudad de Bogotá: Cerros Orientales, Cuenca del Río Tunjuelo y Páramo de Sumapaz; constituye buena parte de la franja de transición urbano rural del borde Sur de Bogotá; cuenta con un total de 9691,7 Has aproximadamente, y comprende la mayor parte del territorio rural de la ciudad. Alcaldía Mayor de Bogotá, s.f. p 58.
} 
En Usme, el contraste entre modos de vida, elementos naturales y procesos de urbanización, como en otros sectores periféricos de las urbes latinoamericanas, ha generado conflictos por uso del suelo, al propiciar la oposición de los habitantes oriundos del sector, en este caso con raíces campesinas, a los acelerados y poco planificados procesos de urbanización.

Respecto a dichas problemáticas, variados estudios confirman la tendencia y resaltan que, en casos como éstos, las problemáticas más relevantes se encuentran asociadas a la ausencia de planeación estatal y a la falta de apropiación y reducida

Figura No. 1

Ubicación del área de estudio

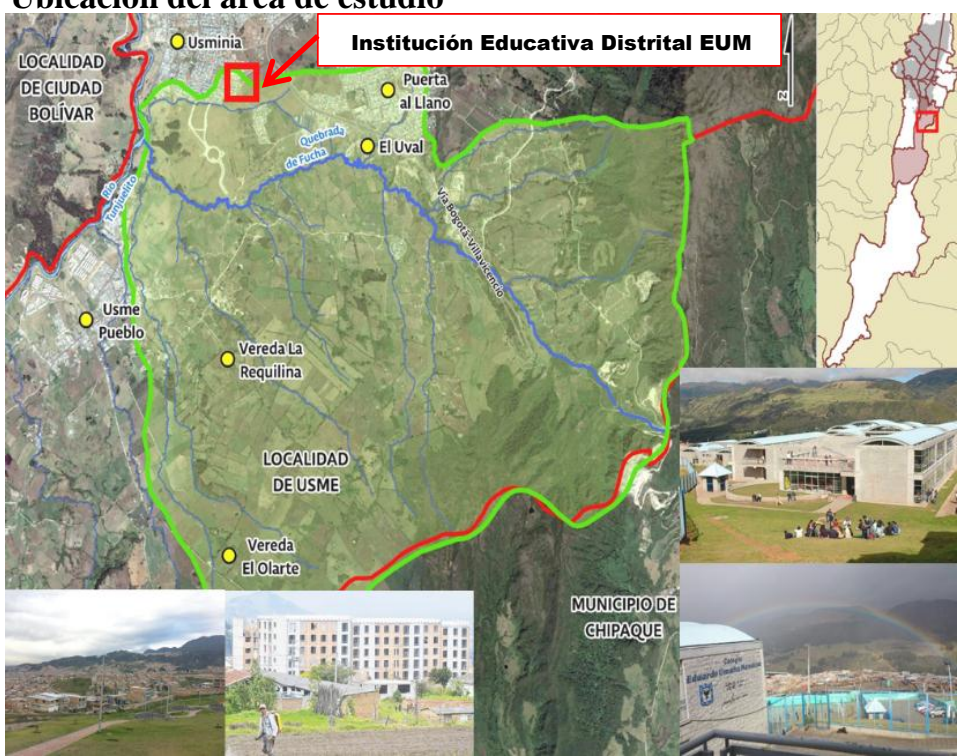

Fuente: adaptación de la autora a partir del archivo digital PRAE EUM 2015 participación de gran parte de pobladores recién llegados a estos territorios, en contraste con el interés de los oriundos en mantener su ruralidad y sus costumbres (Torres, 2015; Ramírez, 2009; Sastoque, 2015).

Así, como lo afirma Leff (1998), los conflictos ambientales son fenómenos importantes a través de los cuales se pueden medir las relaciones sociales y económicas de los territorios, las cuales suelen estar ligadas a un contexto más amplio que tiene que ver con la realidad social, económica y política regional o nacional. En este escenario, la conservación o el cambio de uso de ecosistemas estratégicos suele ser el centro del debate, pues una y otra opción son consideradas como necesidad prioritaria en zonas de transición urbano rural, lo que pone en discusión el cierre o la apertura de los límites al crecimiento urbano, la movilidad rural y los acuerdos en torno al agua, la biodiversidad (Ramírez, 2009) y la conectividad ecológica urbano-rural (Gaitán \& Ruiz 2008).

En el contexto de estudio, confluyen instituciones, organizaciones y empresas, en pro de preservar valores sociales y culturales, así como a favor de la protección de la estructura ecológica y sus elementos naturales, ya que ésta representa para muchos de los pobladores, parte importante de su historia compartida y su sustento. En el proceso de investigación, tanto en la revisión de la literatura como en la aproximación a los actores territoriales, fue posible identificar el trabajo de educación, apropiación y defensa territorial, en algunos casos colectivo y en otros realizado de manera aislada, de organizaciones como: Biblioteca Popular el Uval, Fundación Suasie Yewae, Jardín Botánico de Bogotá, Agro Parque los Soches, Red Juvenil Territorio Sur, Fundación Cerros Orientales, entre otras.

Es en este contexto territorial, en el que están activos distintos conflictos e iniciativas de educación y gestión ambiental, en donde funciona la IED.EUM. A ella asisten estudiantes habitantes de barrios populares, periurbanos y de bajos ingresos económicos, tales como Villa Alemana, Villa Anita, Sucre, Alfonso López, el Brillante y el Tuno, entre otros. Por ello desde 
sus inicios, esta comunidad educativa presentó una propuesta pedagógica socialmente comprometida, cuyo propósito ha sido la transversalidad del currículo a partir de la formación en Derechos Humanos. Los principios filosóficos y pedagógicos del Proyecto Educativo Institucional $(\mathrm{PEI})^{9}$ se encuentran enmarcados en la implementación del modelo pedagógico crítico social. Esto ha llevado a proponer tres ejes de articulación curricular: análisis de la realidad, liderazgo y gestión comunitaria, a partir de los cuales se ha proyectado materializar dichos procesos transversales. Uno de los proyectos transversales es, justamente, el Proyecto Ambiental Escolar (PRAE); éste se vincula a los ejes articuladores del PEI a través de las iniciativas de trabajo que se han desarrollado en la localidad de Usme, y desde donde se ha reconocido la necesidad de implementar una gestión ambiental enfocada y en diálogo con el territorio.

\section{Diseño metodológico}

La investigación fue estructurada como estudio de caso, de tipo cualitativo y en perspectiva descriptiva. El objetivo general consistió en analizar la incidencia de la formación del liderazgo ambiental de los/as jóvenes de la IED.EUM en sus procesos de apropiación territorial, a través del análisis de las iniciativas de formación escolar en liderazgo ambiental desarrolladas en la institución en el periodo 2007-2016 y las formas en las que los/as jóvenes líderes ambientales reconocen y apropian el territorio. El estudio se desarrolló entre el primer semestre de 2015 y el segundo del 2016.

Como participantes en la investigación se contó con los docentes del área de ciencias naturales, los estudiantes de bachillerato de la jornada diurna de la IED.EUM, y los líderes de organizaciones sociales que actualmente apoyan el desarrollo del PRAE, a saber: la Biblioteca Popular El Uval y la Fundación SuasieYewae, junto con dos estudiantes de la Facultad de Licenciatura en Educación Comunitaria de la Universidad Pedagógica Nacional de Colombia $(\mathrm{UPN})^{10}$

Para la aplicación de los instrumentos de convocó aleatoriamente a un grupo de setenta y un (71) estudiantes de la jornada diurna pertenecientes a los ciclos 3,4 , y $5^{11}$ de la IED.EUM, nueve (9)

\footnotetext{
${ }^{9}$ El Proyecto Educativo Institucional (PEI), es la carta de navegación de los colegios, en donde se especifican entre otros aspectos, los principios y fines del establecimiento, los recursos docentes y didácticos disponibles y necesarios, la estrategia pedagógica, el reglamento para docentes y estudiantes y el sistema de gestión. http://www.mineducacion.gov.co/1621/article-79361.html

${ }^{10}$ Estos últimos, en el marco de su proceso de investigación con el comité ambiental de la Institución, como requisito de grado, en donde "a partir de la práctica pedagógica y el ejercicio de caracterización en el contexto urbano-rural del colegio EUM, específicamente del comité ambiental, se buscó desarrollar una aproximación a los aspectos socio-ambientales que tienen incidencia en las relaciones y en la cotidianidad que se teje en el colegio Eduardo Umaña Mendoza". (Cubillos \& Rodríguez, 2016, p. 3).

${ }^{11}$ El ciclo tres (3), agrupa niños y niñas en edades entre 10 y 12 años, en transición de la niñez a la pre adolescencia, en este período de vida los aprendizajes están orientados por la indagación y experimentación. El cuarto ciclo agrupa jóvenes de 12 a 15 años, que corresponden a los grados $8^{\circ}$ y $9^{\circ}$, en donde se fortalece en los estudiantes su capacidad de definición, interpretación, análisis, sistematización y proposición de soluciones a problemas cotidianos. El ciclo cinco (5), agrupa a jóvenes de 15 a 17 años de edad, de los grados $10^{\circ}$ y $11^{\circ}$; abarca la etapa de la adolescencia que se caracteriza por los fuertes cambios intelectuales y psico-afectivos, por el mayor desarrollo de la capacidad reflexiva y de introspección. Secretaría de Educación Distrital. 2012-3. Reorganización curricular por ciclos. p. 47-52. En:http://www.redacademica.edu.co/archivos/redacademica/colegios/politicas_ educativas/ciclos/Cartilla_Reorganizacion_Curricular\%20por_ciclos_2da_Edicion.pdf
} 
estudiantes pertenecientes al Comité Ambiental Escolar (CAE) ${ }^{12}$, cuatro (4) docentes del área de Ciencias Naturales de la jornada diurna y tres (3) líderes ambientales de las instituciones de apoyo al PRAE.

La fase de alistamiento del proyecto incluyó la construcción del estado del arte y la realización de una entrevista piloto a dos líderes ambientales locales; este ejercicio permitió estructurar las categorías y subcategorías de análisis para dar respuesta los objetivos específicos del proyecto, a saber:

1. Caracterizar las iniciativas de formación del liderazgo ambiental implementadas en la IED-EUM en el periodo 2007 a 2016.

2. Reconocer las formas de apropiación del territorio de los jóvenes líderes ambientales.

3. Identificar las potencialidades y limitantes de la Institución educativa en la formación de gestores ambientales juveniles presentes y actuantes en su territorio.

Las categorías estructuradas fueron las siguientes: liderazgo ambiental, territorialidad y procesos de participación de los jóvenes líderes. Estas tres categorías, a la vez, contienen subcategorías y componentes de análisis específicos. (Ver tabla No 2)

Tabla No 2.

Categorías de análisis.

\begin{tabular}{|c|c|c|}
\hline $\begin{array}{l}\text { Categorías de } \\
\text { análisis }\end{array}$ & Subcategorías & Componentes de análisis \\
\hline \multirow{4}{*}{$\begin{array}{l}\text { Liderazgo } \\
\text { ambiental }\end{array}$} & \multirow{2}{*}{$\begin{array}{l}\text { Iniciativa de formación en la } \\
\text { escuela }\end{array}$} & Liderazgo en el ámbito escolar \\
\hline & & Liderazgo dentro de la educación ambiental \\
\hline & \multirow{2}{*}{$\begin{array}{l}\text { Desarrollo de habilidades } \\
\text { personales y sociales }\end{array}$} & Perfil del líder ambiental \\
\hline & & Ejes de la formación del liderazgo ambiental \\
\hline \multirow[t]{5}{*}{ Territorialidad } & \multirow[t]{3}{*}{ Reconocimiento e identidad } & Límites y limitantes del territorio Usme \\
\hline & & Conocimiento y vínculo con su historia y su cultura. \\
\hline & & Problemáticas, necesidad y potencialidades de su territorio \\
\hline & Vivencia & Lugares representativos y apreciados de su territorio \\
\hline & & Conflictos o falencias que afectan su territorio \\
\hline \multirow{4}{*}{$\begin{array}{l}\text { Contexto y } \\
\text { participación de } \\
\text { los jóvenes }\end{array}$} & \multirow[t]{2}{*}{ Características en su contexto } & Jóvenes en el entorno urbano rural \\
\hline & & Características de los/as jóvenes de la Institución Educativa \\
\hline & \multirow[t]{2}{*}{ Participación (sujetos políticos) } & Intereses de los/as jóvenes de la localidad \\
\hline & & $\begin{array}{l}\text { Organizaciones o eventos que propician la participación de los/as } \\
\text { jóvenes. }\end{array}$ \\
\hline
\end{tabular}

Fuente: La autora

Una vez definidas las categorías analíticas, se dio paso al diseño y aplicación de instrumentos. Para el análisis de la categoría 'liderazgo juvenil' y su subcategoría 'iniciativas de formación en la escuela’, se realizó la revisión documental de los textos del PRAE institucional (en sus cuatro

\footnotetext{
${ }^{12}$ Con el acuerdo 166 de 2005, se reglamenta la creación del Comité Ambiental Escolar (CAE) en los colegios públicos y privados de Bogotá con el fin de desempeñarse como órgano asesor en materia ambiental del gobierno escolar; será conformado a partir de un sistemas de selección democráticos, participativos y equitativos, garantizando el acceso voluntario de estudiantes, docentes y padres de familia. Acuerdo $N^{\circ}$ 166. Concejo de Bogotá, D.C.,
} 
versiones de los años: 2010, 2011, 2013 y 2015), con el fin de reconstruir y analizar dicho proceso. Las demás categorías y subcategorías se trabajaron de acuerdo con el siguiente esquema instrumental: mediante análisis documental se identificaron las iniciativas de formación del liderazgo ambiental implementadas en el periodo 2007 a 2016; para así dar paso a la caracterización descriptivita de los procesos de formación de las habilidades tendientes al liderazgo de los jóvenes que conforman el Comité Ambiental Escolar.

Para el reconocimiento de las formas de apropiación territorial, y la identificación de los ejes de formación en liderazgo ambiental que incidieron en los procesos de apropiación territorial de los líderes ambientales juveniles, primero se desarrolló una encuesta semi-estructurada, aplicada de manera personal y simultánea, desde la plataforma Google encuestas a ochenta (80) estudiantes; posteriormente se empleó el paquete estadístico SPSS (StatisticalPackageforthe Social Sciences) para el análisis de las primeras 14 preguntas planteadas en formato de selección múltiple con única respuesta (preguntas 1 a 9) y de múltiple respuesta (pregunta 10 a 15). Los restantes 7 numerales de pregunta abierta, se procesaron en hoja de cálculo Excel, para un posterior análisis de contenido. (Ver formularios en anexos) ${ }^{13}$.

La lectura preliminar de los resultados arrojados por este instrumento, dio paso al diseño de las entrevistas a profundidad para docentes del área de Ciencias Naturales de la Institución y a los líderes ambientales del CAE y de las organizaciones vinculadas a los procesos del PRAE.

\section{Resultados y Discusión}

\section{Inicios del proyecto ambiental EUM}

La consulta en los registros de actas de reuniones de área, los diarios de campo de los maestros y la lectura de los cuatro documentos base del PRAE, permitieron conocer la evolución de los procesos de gestión y las iniciativas de formación en liderazgo ambiental juvenil que se han implementado en la institución en el periodo 2007 a 2016.

El primer documento del proyecto, a solo un año de la fundación de la institución educativa (2008), giró en torno al asocio con la Fundación ProAves, quienes mediaron una relación de intercambio de experiencias con Blue Lake Elementary School del condado de Volusia, en el Estado de la Florida de los Estados Unidos de América y la Organización Compañeros de las Américas. Esta primera experiencia y el reconocimiento del entorno por parte del equipo docente, condujo a un proceso de diagnóstico ambiental, con el fin de determinar las necesidades y ejes de gestión en el contexto territorial en el que recientemente se encontraba inmersa la institución educativa.

\footnotetext{
${ }^{13}$ Formulario encuesta semiestructurada aplicada a estudiantes. 6 de noviembre de 2015. https://www.dropbox.com/s/n84692lq9pdhyuq/FORMULARIO\%20ENCUESTA\%20SEMIESTRUCTURADA\%20 A\%20ESTUDIANTES.pdf?dl=0
} 
Así, a partir de la matriz de diagnóstico ambiental de Goffin, ${ }^{14}$ se delimitó la problemática ambiental local, lo que condujo a identificar las problemáticas y necesidades más sentidas en el territorio desde los sistemas natural, socio-político y cultural. Algunas de las problemáticas definidas fueron: el desbordado crecimiento de viviendas en zonas de reserva, sin los procesos legales $y$ de seguridad adecuados, la deficiente disposición de residuos sólidos, el deterioro del ambiente natural del sector, la afectación directa de las fuentes hídricas, del bosque, la fauna y el suelo. (IED Eduardo Umaña Mendoza, 2010)

Figura No. 2

Capacitación a comunidad en huerta escolar

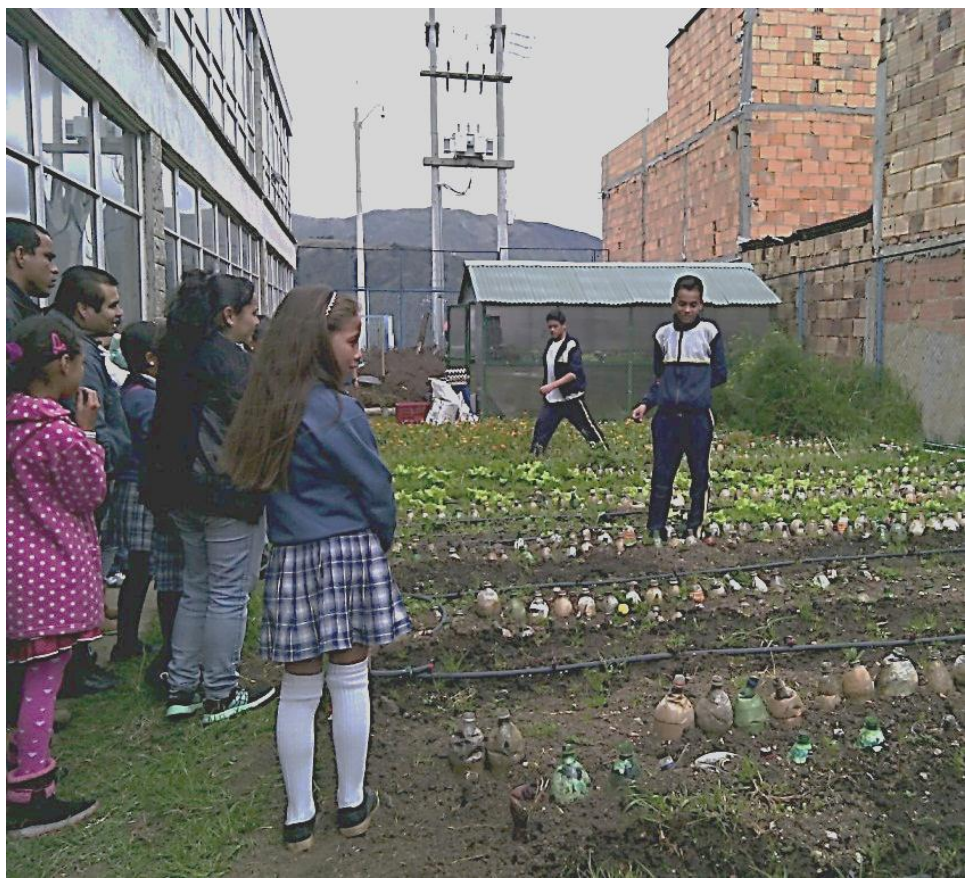

Fuente: Archivo digital PRAE EUM 2015

Estos resultados del diagnóstico,

mostraron la necesidad de trabajar de manera integral sobre las problemáticas identificadas, por lo que se inició en el año 2011 la estructuración de nuevas estrategias de gestión del PRAE, las cuales inician por abordar diversos procesos de formación del liderazgo ambiental, para dar respuesta al objetivo de gestión allí trazado: "Promover y fortalecer en la comunidad educativa, procesos de educación ambiental, encaminados a la conservación de la biodiversidad y la apropiación territorial”. (IED Eduardo Umaña Mendoza, 2010, p. 10).

\section{Las estrategias de acción del proyecto.}

Repensar el Territorio. Esta primera estrategia fue enriquecida con el plan de trabajo presentado por el grupo de investigación de la Universidad Pedagógica Nacional (2013), quienes demuestran al equipo PRAE 2013, la necesidad de que los estudiantes recorran su territorio, reconozcan sus problemáticas y potencialidades, para que desde ellos, surjan las propuestas de acción. En la misma línea, en el año 2014 se efectuó el asocio con la Fundación Suasie Yewae, quienes direccionaron un proyecto de intervención, auspiciado por la Corporación Autónoma Regional $(\mathrm{CAR})^{15}$ dentro de la localidad de Usme. Los/as jóvenes CAE iniciaron con ellos procesos de

\footnotetext{
${ }^{14}$ Louis Goffin (1995), define el diagrama de Goffin, como un instrumento que posibilita el tránsito de un pensamiento lineal a un pensamiento sistémico. Integra el análisis del espacio, los recursos, las poblaciones y la sociedad, para poder comprender cómo interactúan los grupos humanos con los recursos, en el espacio que habitan, atendiendo a diversas relaciones de las realidades ambientales. (Alcaldía de Bogotá, 2010)

${ }^{15}$ Las Corporaciones Autónomas Regionales y de Desarrollo Sostenible (CAR) son entes corporativos de carácter público, integrados por las entidades territoriales, encargados por ley de administrar -dentro del área de su jurisdicción- el medio ambiente y los recursos naturales renovables, y propender por el desarrollo sostenible del país. Colombia. Ministerio de medio Ambiente y Desarrollo Sostenible.
} 
formación ambiental alternos a los desarrollados en la institución: recorridos de reconocimiento territorial, jornadas de reforestación en los cauces de fuentes hídricas del sector y un campamento de formación en fotografía ambiental y documental.

Así, dicha estrategia agrupa dentro de sus actividades: los recorridos territoriales, embellecimiento de espacios en la zona aledaña a la institución y salidas de reconocimiento de la cuenca media del río Tunjuelo y sus afluentes; Esto ha permitido a los estudiantes, mirar sus espacios comunes desde otras perspectivas, interactuar con el territorio, reconocerlo como un elemento vivo y participar de su gestión. (Contreras \& Téllez, 2015).

Transformación de Hábitos. Dentro de esta segunda estrategia de gestión, se inició en el año 2011 la adecuación del espacio para establecer la huerta escolar como aula ambiental, apoyada con el programa de manejo integral de residuos sólidos. Para ello, se emprendieron procesos de capacitación por parte de los estudiantes en sus hogares, en técnicas de clasificación en la fuente y aprovechamiento de los residuos de origen orgánico para Figura No. 3

Capacitación a comunidad en líneas de acción del PRAE

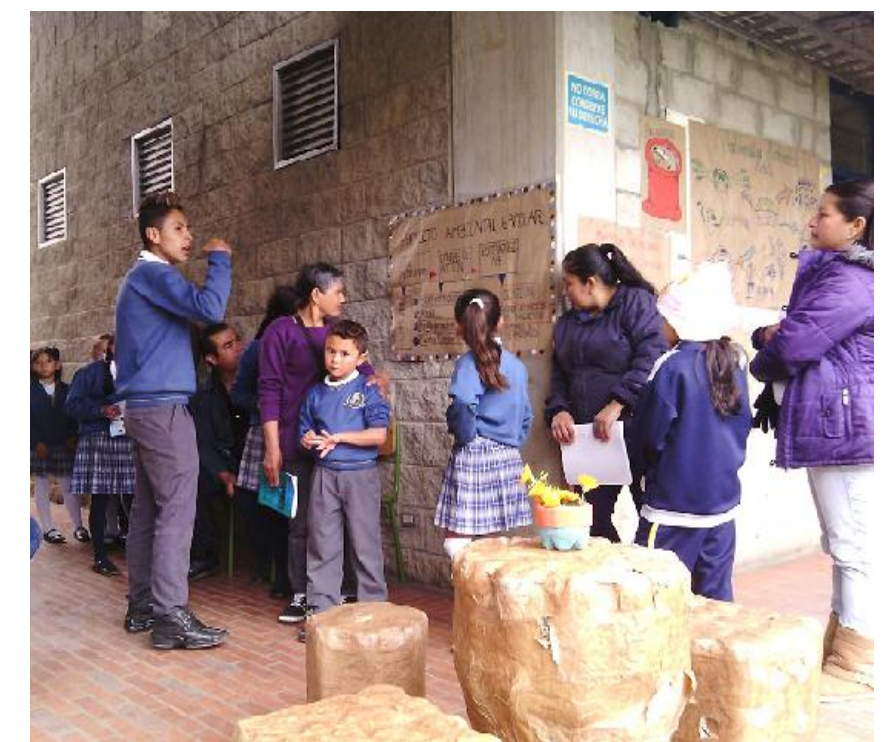

Fuente: Archivo digital del Proyecto Ambiental Escolar (PRAE) IED. EUM 2015. Se muestra el trabajo socialización del proyecto y exhibición de muebles elaborados con botellas PET a miembros de la comunidad educativa. producción de abonos, junto con el acopio y transformación de reciclables y elaboración de ladrillos ecológicos con botellas $\mathrm{PET}^{16}$ (Ver figura $\mathrm{N}^{\circ} 3$ ). Con estos últimos se ha llevado a cabo la construcción de buena parte de la huerta escolar. Dentro de estos procesos, se suma la iniciativa de generar material didáctico para capacitar estudiantes de básica primaria en estos temas.

Participación y acción. Esta tercera estrategia, agrupa las acciones de participación de los estudiantes líderes del Comité Ambiental Escolar en diversos encuentros de formación, diálogo e intervención ambiental. Allí, se estrechan vínculos con entidades de apoyo y se da la participación conjunta de estudiantes y docentes en talleres de formación y mesas de trabajo. El contar con el liderazgo de algunos de los estudiantes, les ha permitido participar en discusiones sobre las problemáticas de su territorio con autoridades ambientales regionales como la CAR, frente a las cuales han tenido la oportunidad de sentar una postura y formarse para la acción y el

\footnotetext{
https://www.minambiente.gov.co/index.php/component/content/article?id=885:plantilla-areas-planeacion-yseguimiento-33

${ }^{16}$ Una solución tecnológica llamada construcción con botellas, un sistema de autoconstrucción que utiliza las botellas PET (plásticas) no retornable a manera de ladrillos. Las botellas se rellenan con tierra u otros materiales del lugar y se vinculan unas a otras por medio de tensores formando un sistema biomimétrico. En: Ruiz Valencia, D., López Pérez, C., Cortes, E., \& Froese, A. (2012). Nuevas alternativas en la construcción: botellas PET con relleno de tierra. http://revistas.javeriana.edu.co/ p. 295
} 
pensamiento creativo. Dentro de este proceso de formación y diálogo propiciado por la CAR, en el año 2015 fueron certificados como promotores ambientales juveniles tres estudiantes líderes del proyecto. (IED Eduardo Umaña Mendoza, 2015)

\section{Alcances y limitantes de las iniciativas de formación del liderazgo ambiental.}

La revisión documental y el diálogo con los docentes y líderes de las organizaciones, muestran la evolución de los procesos que se lideran a través del proyecto y los múltiples esfuerzos que se han hecho a partir de cada una de las estrategias de acción para formar a los integrantes CAE como líderes ambientales comunitarios (Ver Figura $\mathrm{N}^{\circ}$ 4), lo que potencia en estos estudiantes que permanecen en el proceso, el desarrollo de habilidades sociales $\mathrm{y}$ personales que les permite ponerse al frente de sus comunidades en ámbitos sociales, políticos y académicos con apropiación del territorio, trascendiendo con su ejemplo como líderes de sus grupos etarios.

Los docentes líderes del proyecto afirman que los estudiantes demuestran una alta preocupación sobre cuestiones ambientales que afectan a su localidad y muchos opinan y proponen acciones desde sus percepciones y vivencias; se muestran curiosos, y preguntan sobre los sucesos de su territorio.

Los estudiantes que se han mantenido en el proceso del CAE por más de un año, demuestran mucha seguridad al momento de enfrentar un auditorio, son más influyentes en sus grupos de clase y propositivos al momento de enfrentar una situación problema. Al respecto plantea uno de los estudiantes líderes con la mayor permanencia en el CAE: "Tenemos una formación en liderazgo y muchos ya damos frutos, nos forman desde un pensamiento crítico. Opinamos y profundizamos en los argumentos".
Figura $\mathrm{N}^{\circ} 4$.

Evolución PRAE del Colegio Eduardo Umaña Mendoza -IED

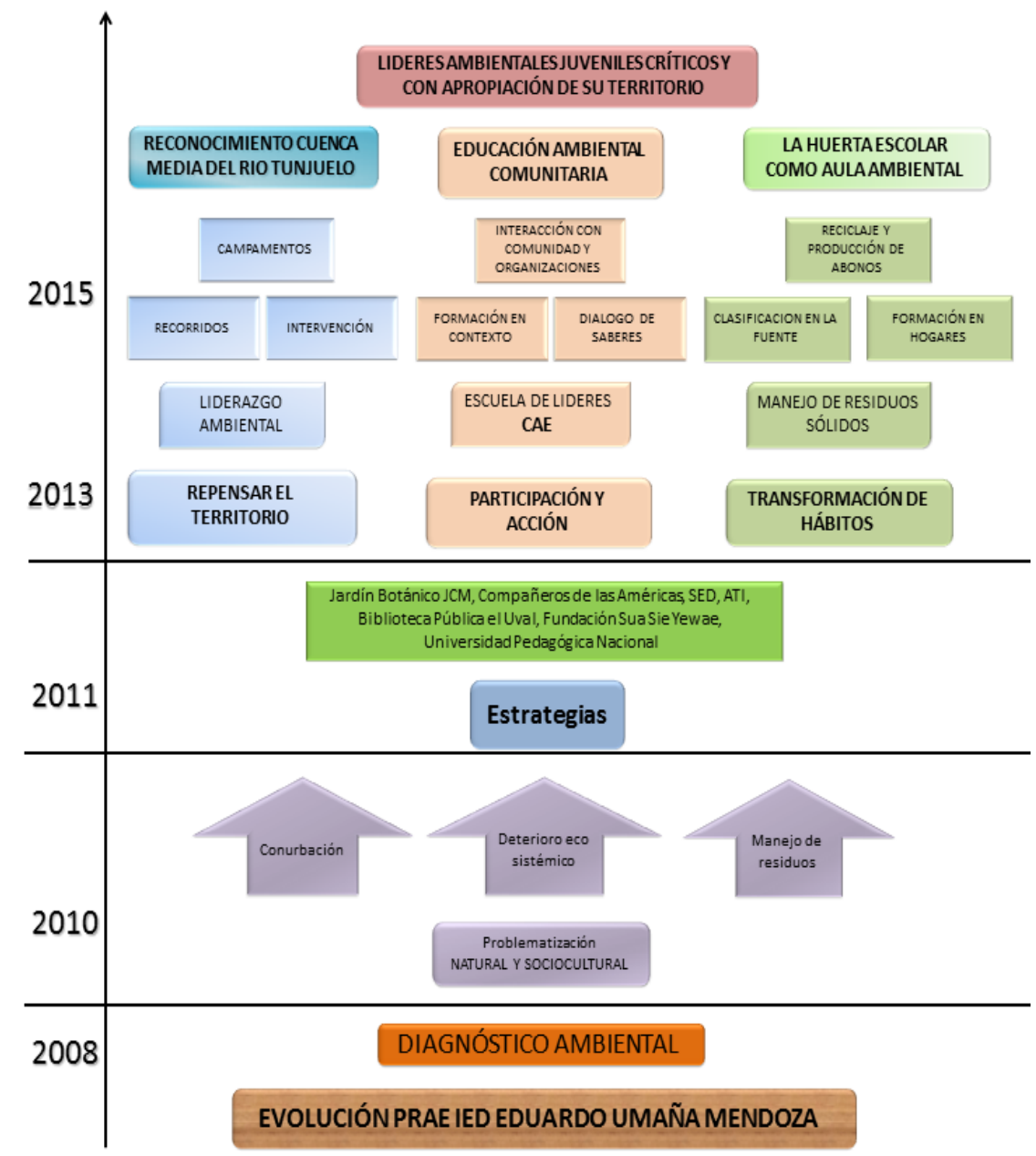

Fuente: La autora. Síntesis de la descripción de componentes y evolución del PRAE de la Institución a partir del análisis documental. 
La evolución del PRAE de la institución en los últimos cuatro años ha permitido encaminar la planeación de las actividades, en dirección a los ejes de gestión y formación del liderazgo ambiental, que como lo propone Pascagaza et. al., (2010), deben priorizar: el encuentro, el intercambio de experiencias, la identificación de situaciones ambientales, la circulación de discursos, el reconocimiento de los contextos, la planeación de acciones y la participación comunitaria, usando diferentes espacios, procesos y estrategias (Ver Tabla No 3).

Tabla No 3.

Ejes de formación del liderazgo ambiental en la IED.EUM

EJES DE FORMACIÓN

\section{DESCRIPCIÓN DE COMPONENTES}

Encuentro, intercambio de experiencias y circulación de discurso

Reconocimiento de contextos e identificación de situaciones ambientales

Planeación y gestión participativa CAR, la Secretaria de Ambiente y la fundación SuasieYewae.
El trabajo en este eje incluye reuniones periódicas de los integrantes del CAE con los docentes y líderes de las organizaciones de apoyo al proceso PRAE, los estudiantes socializan sus logros y dificultades de los procesos de gestión que tienen a cargo dentro y fuera de la Institución: Participación en la planeación y ejecusión de actividades de la huerta escolar, seguimiento a los procesos de transformación de residuos sólidos, sensibilización ambiental escolar y gestión territorial. Resultados preliminares de este proceso de empoderamiento fueron canalizados en el mes de septiembre de 2016 en un evento liderado por el equipo CAE, al cual fueron convocados los colegios de la localidad e Instituciones comunitarias y gubernamentales a participar en "la Primera Feria Agroecológica Eduardo Umaña Mendoza".

Los recorridos territoriales, los conversatorio CAE, las salidas pedagógicas y los talleres liderados por las instituciones de apoyo, son las principales actividades que enriquecen este eje de formación; a partir de estos eventos los estudiantes han podido reconocer las problemáticas y potencialidades de su territorio y desde allí, participar y emprender por cuenta propia y en compañía de estudiantes de otras instituciones, proyectos de gestión ambiental en el marco de las Estrategias de Mitigación para el Cambio Climático, que lidera la Corporación Autónoma

Este nuevo eje de formación surge a partir del dialogo y análisis desde diferentes frentes de gestión, por un lado la participación de los estudiantes en procesos de formación y certificación como Promotores Ambientales, los resultados del trabajo de investigación de los estudiantes tesistas UPN y el desarrollo de la presente investigación; eventos que llevaron a identificar la necesidad de planificar los procesos de gestión ambiental desde un enfoque participativo en donde el diálogo con la comunidad educativa ha sido determinante. A partir de allí, se planeó a finales del año 2015, la Feria Agroecológica 2016, como un espacio de encuentro, participación y consolidación de redes de cooperación interinstitucional.

Fuente: El Autor. Síntesis de las actividades que se desarrollan en cada uno de los ejes de formación del liderazgo ambiental con los estudiantes participantes en el comité ambiental escolar EUM.

No obstante, al contrastar dichas iniciativas con la visión de docentes y estudiantes, parece que estos esfuerzos no son suficientes y que es necesario, como lo sugiere la ley ${ }^{17}$, que este componente trasversal se estructure con mayor acierto en la escuela, pues los resultados son lentos y, a la vez, es muy escaza la continuidad de los estudiantes en este tipo de procesos, pues de grupos de 40 estudiantes que se inscriben en el proyecto al iniciar el año escolar, tan solo un $30 \%$ se mantienen de manera constante, tal como lo demuestran los registros del proceso. (Ver

\footnotetext{
17، Los Proyectos Ambientales Escolares (PRAE), incorporarán, a las dinámicas curriculares de los establecimientos educativos, de manera transversal, problemas ambientales relacionados con los diagnósticos de sus contextos particulares, (...) que permitan a los niños, niñas y adolescentes, el desarrollo de competencias básicas y ciudadanas, para la toma de decisiones éticas y responsables, frente al manejo sostenible del ambiente". Artículo $8^{\circ}$ Ley 1549 de 2012.
} 
formularios anexos $)^{18}$. Esto, por la confluencia de múltiples circunstancias, entre las que se encuentran, en primer lugar, las dinámicas formativas desarticuladas que muchas veces se dan al interior de la institución y que obstaculizan el proceso, pues una parte del colectivo docente se rehúsa a reconocer la formación que los estudiantes adelantan dentro de las actividades PRAE en un proceso académico evaluativo más flexible e integral, no solo asignaturista, lo que ha traído como consecuencia que los participantes se desaminen ante la posibilidad de reprobar las asignaturas académicas.

Por otro lado, afirman los docentes líderes del proyecto, que a pesar de contemplarse el liderazgo como uno de los ejes articuladores del PEI, no se evidencia el compromiso por planear las acciones tendientes a la formación de dichas habilidades desde todas las áreas del saber, y cuando lo hacen, es de manera aislada y desarticulada. Los estudiantes muchas veces desconocen la intencionalidad de los procesos en los que participan; esto lo confirma la encuesta aplicada a estudiantes, pues al indagar acerca de cómo creen que es la formación del liderazgo en la institución, el $43 \%$ afirma que es deficiente, escasa o no tiene conocimiento de dicho proceso ${\text { (Pregunta } \mathrm{N}^{\circ} \text { 7. Encuesta a estudiantes) }}^{19}$.

En contraste con estos resultados de la encuesta, en la entrevista personal, ${ }^{20}$ los estudiantes líderes CAE coinciden en afirmar que los procesos desarrollados dentro de la Institución a través de los ejes articuladores del PEI, los fundamentos del modelo socio-crítico y estrategias como la Semana de énfasis ${ }^{21}$, implementadas dentro de la Institución en los últimos seis años, han generado en gran parte del colectivo estudiantil, importantes habilidades comunicativas, pensamiento crítico y capacidades de argumentación, que si se canalizan y fortalecen adecuadamente, representan un potencial importante que permitirá posicionar a la Institución como líder en la formación de gestores comunitarios. Sin embargo, plantean que esto será posible si se encaminan dichas habilidades a procesos de gestión como en los que ellos participan a través del CAE, pues el común de los estudiantes adolecen de falta de espacios para interactuar en su contexto. Estas afirmaciones son apoyadas por los resultados del proceso de investigación adelantado por las estudiantes tesistas de la UPN, quienes afirman que la formación en pedagogía

\footnotetext{
${ }^{18} \mathrm{https} / / /$ www.dropbox.com/s/084lj62vsc97qxa/SEGUMIENTO\%20ESTUDIANTES\%20CAE\%202014\%20Y\%202015.xlsx?dl= 0

${ }^{19}$ Formulario encuesta semiestructurada aplicada a estudiantes. 6 de noviembre de 2015. https://www.dropbox.com/s/n84692lq9pdhyuq/FORMULARIO\%20ENCUESTA\%20SEMIESTRUCTURADA\%20 A\%20ESTUDIANTES.pdf?dl=0

${ }^{20}$ Entrevista personal con líderes CAE. 3 de mayo de 2016. En: https://www.dropbox.com/s/2nehivgr8u32596/ENTREVISTA\%20PERSONAL\%20CON\%20ESTUDIANTE\%20L\%C3\%8DDE RES\%20DEL\%20COMIT\%C3\%89\%20AMBIENTAL.pdf?dl=0

${ }^{21}$ Semana de Énfasis (SE) es una estrategia de aprendizaje implementada en el ciclo cuatro de la Institución Educativa Distrital -IED- Eduardo Umaña Mendoza al finalizar cada periodo escolar. La estrategia busca crear más tiempo de aprendizaje y hacerlo más continuo, por eso se destinan treinta horas, una semana, para que con estudiantes de los diferentes cursos del ciclo, se desarrolle un proyecto en el contexto de los tres ejes articuladores del PEI. Pinzón, P. \& Sarmiento, R. (2015). Una semana sin horario: estrategia para reorganizar la escuela por ciclos.p 56. intellectum.unisabana.edu.co.
} 
crítica $^{22}$, sumada a los orígenes periurbanos de los/as jóvenes, representa un gran potencial para la gestión comunitaria de la localidad. ${ }^{23}$

\section{La apropiación territorial de los jóvenes líderes ambientales.}

Las características de la población de estudio de esta investigación y de su territorio, catalogado como perteneciente al borde urbano rural suroriental de Bogotá, nos lleva a caracterizar los jóvenes en su entorno rural o periurbano, con el fin de entender las particularidades y necesidades propias de su contexto.

Los procesos de apropiación territorial en entornos urbano rurales, requieren reconocer la superposición de múltiples territorios, destacándose el cultural, económico y ambiental, con diferentes enfoques por influencia de la diversidad generacional (IICA, 2000). Se trata de reconocer lo rural como un territorio que tiene una integración particular de recursos naturales, sociales y culturales, en donde el aporte de las generaciones jóvenes reviste mayor importancia que en situaciones históricas anteriores (Sepúlveda, S., Castro, A. \& Rojas, P., 1998) debido a, entre otras variables, los acelerados avances tecnológicos que impregnan todos los ámbitos sociales y por supuesto, no es la excepción para el desarrollo rural. Son estas nuevas generaciones las que con mayor facilidad se adaptan a los cambios, emergiendo en ellos nuevas ruralidades (IICA, 2000).

En la IED.EDM, los jóvenes participantes de los proyectos institucionales son conscientes de estos cambios y responsabilidades que implica habitar su territorio; reconocen el valor del campesino dentro de su cotidianidad y en las relaciones próximas con la urbe que los circunda y, a la vez, se reconocen ellos mismos como integrantes de estas nuevas ruralidades. ${ }^{24}$ En términos de los docentes del área de ciencias naturales, los estudiantes se ven vinculados a su territorio al vivenciar los espacios de la localidad como parte de su cotidianidad. Juegan en el parque, en alguna época visitan el rio con sus amigos y familiares o se desplazan por la zona rural hacia el pueblo de Usme. También algunos caminan largas distancias para llegar al colegio y en este trayecto exploran los aspectos positivos y negativos de su territorio. (Entrevista personal con docentes de ciencias naturales EUM, noviembre de 2015).

Los estudiantes CAE reconocen las fronteras geográficas de la localidad y las relacionan con las cualidades ambientales que ésta posee, como el páramo, los ecosistemas limítrofes con los municipios aledaños y las fuentes hídricas. Plantean como potencialidades de su territorio, el

\footnotetext{
${ }^{22}$ La pedagogía crítica ve la educación como una práctica política, social y cultural, a la vez que se plantea el rechazo a las relaciones de salón de clases que descartan la diferencia. Martínez, L. (2006).

${ }^{23}$ “ El espacio escolar del EUM, posee un gran potencial político, crítico, y analítico, frente a las dinámicas territoriales, pasando por iniciativas e innovaciones pedagógicas, con un sentido trasformador con la comunidad, enfocándolo en un contexto barrial y rural haciendo mella en las subjetividades políticas y socio económicas, y la importancia de la memoria y en la defensa del ambiente". Cubillos, Y. \& Rodríguez, A. (2016). Umañistas por el Territorio: una experiencia investigativa y pedagógica hacia la construcción de una educación ambiental y comunitaria en la escuela. Universidad Pedagógica Nacional. p 32.

24 "Una mirada a las concepciones frente a las Nuevas Ruralidades". Por: La Corporación Educativa y de Desarrollo Social "Hilando Sueños", la Red Juvenil UBUNTU, El programa Nacional de Concertación Cultural del ministerio de Cultura y El colegio Eduardo Umaña Mendoza IED, de la ciudad de Bogotá ubicado en la Localidad Quinta de Usme. https://www.youtube.com/watch?v=Zc7NiLTEPkI
} 
poder realizar actividades de esparcimiento, recreativas, culturales y de ecoturismo. Consideran como limitantes para el trabajo comunitario: las problemáticas de inseguridad asociadas al consumo de drogas y pandillismo; la apatía, pereza y desarraigo de muchos pobladores; la indiferencia social y poca presencia estatal frente a las problemáticas sociales y ambientales. (Encuesta: Preguntas $\mathrm{N}^{\circ} 13,14,16$ y $17^{25}$ y Entrevista a líderes $\mathrm{CAE}^{26}$ )

Puntualizando en estos factores, que consideran una limitante para sus procesos de gestión ambiental, uno de los estudiante líder del CAE, plantea que algunos de los habitantes de la zona con origines campesinos, "se interesan solo por sus propias necesidades y proyectos, son poco participantes", quizá por la arremetida violenta de la urbanización ilegal o también por la pobreza, "se han desinteresado de su territorio, ansían estar en la ciudad y algunos ya no valoran su entorno", 27 hay una buena población en desarraigo. Esta postura la apoya también la percepción de los docentes, al plantear que la localidad y específicamente el barrio, posee una población que se ha visto obligada a habitar hace poco el territorio ${ }^{28}$ y por ende no siente arraigo y desconocen su valor cultural ${ }^{29}$.

Como lo afirman las tesistas de la Universidad Pedagógica Nacional, los estudiantes del comité ambiental ven el su territorio un potencial, reconocen el entorno urbano rural que los circunda, logran percibir que es necesaria una articulación de estos dos espacios y a pesar de las diversas problemáticas de su territorio, encuentran en la zona rural una fuente de alimento, distensión y contacto natural. En contrate las docentes de ciencia naturales de la institución, plantean que ellos muestran sensibilidad a los problemas ambientales y entienden que la comunidad tiene la capacidad de cambiar sus condiciones, sin embargo, las diversas situaciones sociales que viven, desbordan su forma de ver la vida y en algunos casos los lleva a alejarse de la idea de trabajar en comunidad.

No obstante, es importante considerar que son las nuevas generaciones quienes pueden romper con los círculos de pobreza en este tipo de contextos, si se les ayuda a generar las condiciones para salir de esta encrucijada. Las transformaciones sociales aceleradas que han modificado la organización sociocultural de los espacios urbano rurales, han desencadenado nuevas formas de percibir el entorno, al igual que las relaciones de poder en dichos contextos, generándose nuevas institucionalidades. En donde los gobiernos locales, las organizaciones y los estamentos educativos, tenemos la oportunidad de ser núcleos generadores de participación y gestión para el desarrollo local participativo, vinculando como protagonistas a la población juvenil (IICA, 1998).

\footnotetext{
${ }^{25}$ Formulario encuesta semiestructurada aplicada a estudiantes. 6 de noviembre de 2015. https://www.dropbox.com/s/n84692lq9pdhyuq/FORMULARIO\%20ENCUESTA\%20SEMIESTRUCTURADA\%20 A\%20ESTUDIANTES.pdf?dl=0

${ }^{26}$ Entrevista personal con líderes CAE. 3 de mayo de 2016. En: https://www.dropbox.com/s/2nehivgr8u32596/ENTREVISTA\%20PERSONAL\%20CON\%20ESTUDIANTE\%20L\%C3\%8DDE RES\%20DEL\%20COMIT\%C3\%89\%20AMBIENTAL.pdf?dl=0

${ }^{27}$ Entrevista personal con líderes CAE. 3 de mayo de 2016.

28 "Bogotá tiene la mayor recepción de víctimas del conflicto" La mayor concentración de víctimas se ubica en las localidades de Ciudad Bolívar (28.813 personas registradas), Bosa (21.067), Kennedy (20.659), Suba (15.251), San Cristóbal (13.003), Usme (12,112), Engativá (8.387). Diario El universal. Octubre de 2016. ${ }_{29}$ ttp://www.eluniversal.com.co/colombia/bogota/bogota-tiene-la-mayor-recepcion-de-victimas-del-conflicto-135858.
} 
Es así que los jóvenes en este contexto reclaman el liderazgo, el cual debe darse multidimensionalmente, pues como los responsables de su formación, hay que tener la capacidad de promover el liderazgo en los entornos económico, social y político, teniendo como constante "la participación social y la concertación política, para enfrentar los retos que presenta la equidad económica, la sostenibilidad ambiental y la construcción de identidades culturales". (IICA, 2000, $\mathrm{p}, 16)$

\section{Potencialidades y limitantes de la Institución educativa en la formación de gestores ambientales juveniles.}

En contexto, la escuela, más que ser un espacio físico, tiene toda una connotación sociocultural y constituye un espacio de identidad y diferenciación. Por ello, deben aprovecharse cada uno de sus espacios académicos para estrechar lazos entre los estudiantes, su entorno y sus múltiples dinámicas. En este sentido, los/as jóvenes de la institución que no han participado del CAE, consideran que no tienen espacios para conocer e intervenir frente a las problemáticas de su territorio, les gustaría poder hacerlo, pues algunos que si actúan, están vinculados a otros espacios de participación, próximos pero sin interlocución con la escuela. (Preguntas $\mathrm{N}^{\circ}$ 20, 21 y 22. Encuesta a Estudiantes).

Esto también se puede evidenciar al indagar frente a cuál ámbito o escenario social ha contribuido más en su formación como líder (Pregunta $\mathrm{N}^{\circ} 11$. Encuesta a Estudiantes). El 35\% de los encuestados plantean que la escuela, mientras el $44 \%$ plantea que los grupos juveniles, la Iglesia u organizaciones de trabajo comunitario y ambiental. De otra parte, el $19 \%$ de los encuestados plantea no ser influenciado desde ningún ámbito formativo o de participación local.

Pensar la formación de líderes ambientales comunitarios, requiere contemplar factores como la cultura y su contexto, caracterizando el tipo de sujeto que se quiere para ese lugar, y el perfil del líder ambiental que éste necesita; dotarlo de conocimientos, sentidos y acciones que pueden ser propias de un líder, capaz de proponer alternativas frente a las necesidades de su entorno. (Tovar\& Gálvez, 2012) En este contexto se interrogó a los docentes de Ciencias Naturales de la IED.EUM acerca de Cómo se debe formar un líder ambiental. La siguiente respuesta recoge la mayoría de componentes hasta aquí citados:

"Un líder ambiental debe formarse de manera integral abarcando aspectos de carácter conceptual, psicológico - emocional, ético, de participación, y de comunicación en escenarios formales, pero sobre todo en escenarios de educación no formal (encuentros, foros, mingas, etc.), de manera que logre comprenderse a sí mismo como un sujeto y se emancipe al reconocer en los otros y en su propia cultura, el conocimiento que le permita en diferentes ámbitos aprender de manera autónoma y actuar en consecuencia con una mirada crítica". (Entrevista personal con el docente William Tupaz, noviembre de 2015)

En síntesis, la comprensión del territorio es el punto de partida para que se den los procesos de territorialidad que sustentarán la gestión ambiental, pues en definitiva, "no se puede cuidar lo que no se ama, y no se puede amar lo que no se conoce" (Anónimo) y si no se conoce, tampoco se comprende. Es aquí donde el sentido de apropiación cobra valor; la interacción de las personas con los entornos y sus principales efectos están determinados por la identidad de lugar. "La apropiación territorial aporta elementos teóricos y empíricos que permiten investigar e intervenir 
modos de interacción social más eficaces, justos y adecuados a las demandas sociales actuales." (Vidal, y Pol, 2005, p.1)

El consolidar los ejes de formación del liderazgo ambiental: Encuentro, intercambio de experiencias y circulación de discurso; Reconocimiento de contextos e identificación de situaciones ambientales; Planeación y gestión participativa, llevo a estructurar mecanismos de autogestión por parte de los estudiantes líderes ambientales, que les ha permitido de manera efectiva, trascender las limitaciones del contexto escolar y disciplinar, hacia procesos consistentes de apropiación territorial y empezar a trascender con su ejemplo, en otros miembros de la comunidad educativa umañista, que redunda de manera positiva en su territorio.

Así, es preciso continuar desde las relaciones sociales existentes, para potenciar las destrezas, habilidades y capacidades asociadas a la toma de decisiones participativas para el bien común (IICA, 2000), en donde los/as jóvenes gestionen de manera efectiva su entorno con actividades que propicien el desarrollo local, usando la investigación, gestión institucional, social y política hacia programas fundados en procesos de planeación participativa, que apunten a las necesidades prioritarias en sus contextos y conecten la Institución educativa con las comunidades, cumpliendo así con el objetivo primordial que debe perseguir todo Proyecto Ambiental Escolar (PRAE).

\section{Conclusiones}

Los procesos y espacios que brinda el Proyecto Ambiental Escolar PRAE del colegio Eduardo Umaña Mendoza-IED son un escenario propicio para estructurar actividades que involucren la investigación, gestión institucional, social y política, en donde los jóvenes gestionen, a partir de mecanismos de planeación participativa, la defensa de su territorio y se den transformaciones sociales que redunden en el desarrollo local.

Es necesario trascender a partir de la propuesta de formación de líderes ambientales a otros espacios de la escuela, permitiendo integrar estas iniciativas con los diversos procesos formativos y comunitarios que componen y acompañan el entorno escolar y así, propiciar el díalogo y los escenarios de participación que los estudiantes reclaman.

La conformación territorial tiene especial importancia para los jóvenes que se desenvuelven en un entorno urbano rural; ellos demuestran cierto dominio e interés por su territorio, pues es allí donde establecen relaciones con sus pares (Guerrero, 2009). Circunstancia que se debe aprovechar para la formación del liderazgo juvenil ambiental, con la integración de los componentes que especifica la educación ambiental, sumada al reconocimiento de los actores y espacios de participación de los contextos, y así, estructurar procesos fuertes de gestión comunitaria, que reconozcan las condiciones y necesidades educativas, históricas, sociales, culturales, de identidad, económicas y políticas de los jóvenes.

Las relaciones y procesos que al interior de la IED.EUM se realizan, en términos de la formación del liderazgo, son insuficientes y desligadas unas de otras; allí, el componente ambiental, caracterizado como una de las problemáticas más sentidas y evidenciadas dentro de la comunidad estudiantil, es trabajado de manera desarticulada y casi que exclusiva dentro de las actividades propuestas por el PRAE, sin diálogo e interacción con los espacios académicos que mantienen un 
esquema asignaturista en la planeación, implementación y evaluación educativa.

Los/as jóvenes se encuentran en busca de espacios de convergencia social, hay una sinergia entre los términos juventud y participación. Así, la escuela debe brindarles herramientas que les permitan conectar de manera más visible y vivencial, las actividades escolares con sus procesos de territorialidad.

Potenciar las habilidades de liderazgo en los/as jóvenes, propiciar que vuelvan las miradas a sus raíces, fortalecer lazos con su territorio, permitirá desde la escuela, brindarles herramientas a los jóvenes para hacerse partícipes de nuevas apuestas y proyectos de gestión ambiental territorial.

La estrecha relación entre gestión y educación ambiental, son eventos que dependen en gran medida del liderazgo propio del gestor; por ello, la urgencia de generar desde la escuela espacios diversos que promuevan el ejercicio de habilidades de liderazgo, que posibiliten una efectiva gestión ambiental en comunidades inmersas en dinámicas y conflictos territoriales tan complejos como los que configuran el territorio de estudio.

\section{Referencias.}

Barbuto, J. E., \& Burbach, M. E. (2006).The emotional intelligence of transformational leaders: A field study of elected officials. The Journal of social psychology National Library of Medicine, 20894 USA. 146(1). p. 51-64.

Bass, B.M. and Riggio, R.E. (2006), Transformational Leadership, Lawrence Erlbaum, Mahwah.

Castrillón, G, \& García, Y. (2009). Aproximación a un estado del arte de la didáctica en la educación ambiental. Colombia: Universidad de Antioquia. Colombia.

Caputo, L. (2006). Estudios sobre Juventud Rural en América Latina. Limitaciones y Desafíos para una Agenda de Investigación sobre Juventud Rural. BASE - IS. Disponible en http://juventudruralemprendedora.procasur.org/wpcontent/uploads/2013/08/Ana\%CC\%81lisis-sobre-los-Estudios-sobre-Juventud-Rural-enAme\%CC\%81rica-Latina.pdf

Chetty, S. (1996). The case study method for research in small-and medium-sized firms. International small business journal, 15(1), 73-86.

Clark \& Wallace. (s.f) Interdisciplinary environmental leadership. Learning and Teaching Integrated Problem Solving. Disponible en: http://www.academia.edu/2647397/ Interdisciplinary_environmental_leadership_learning_and_teaching_integrated_problem_solvi ng.

Colombia. Ministerio de Medio Ambiente MMA y Ministerio de Educación nacional MEN. (2002). Política Nacional de Educación ambiental [SINA].

Colombia. Ministerio de Educación Nacional MEN (2002). Plan Decenal de Educación 19962005. Pacto social por la educación. p.23-60 
Colombia. Ministerio de Educación Nacional MEN (2002). Plan Decenal de Educación 2006 2016 Pacto social por la educación. p.23-60

Comité Operativo Distrital de Infancia y Adolescencia. CODIA. (2011). La política de Infancia y Adolescencia en Bogotá D.C. 2011 - 2021. Alcaldía Mayor de Bogotá.

Contreras, T. \& Téllez, C. (2015). Caracterización ambiental del territorio como estrategia pedagógica destinada al cuidado y preservación del componente hídrico en las instituciones educativas distritales Eduardo Umaña Mendoza y Quiroga Alianza. (Tesis de maestría). Universidad Jorge Tadeo Lozano. Bogotá.

Cubillos \& Rodríguez (2016). Umañistas por el territorio: Una experiencia investigativa y pedagógica hacia la construcción de una educación ambiental comunitaria en la escuela. Universidad Pedagógica Nacional. Colombia.

Escobar, A. (2000) El lugar de la naturaleza y la naturaleza del lugar: ¿globalización o postdesarrollo? En: Viola, A. (2000). Antropología del Desarrollo. Editorial Paidós, Barcelona.

Freire, P. (2002). Concientización: teoría y práctica de una educación liberadora. Buenos Aires: Editorial Galerna - Búsqueda de Ayllu.

Gaitán Uribe, M. M., \& Ruiz Tinedo, F. L. (2008). Conectividad ecológica en la zona urbanorural en la localidad de Suba.

Goleman, D. (1999). La Práctica de la Inteligencia Emocional. Barcelona. Disponible en: http://webs.uvigo.es/pmayobre/master/textos/Evangelina_garcia/practica_inte_emocional.pdf.

Guerrero, L (2009). Categorías etéreas. ¿Juventudes campesinas? Nuevas formas de socialización e identidad en el campo. En L. y. (Editores), Las configuraciones de los Territorios Rurales en el siglo XXI (págs.597-629).Bogotá: Editorial Pontificia Universidad Javeriana.

Hiernaux, D., \& Lindón, A. (2004). Desterritorialización y reterritorialización metropolitana. Documentsd'analisigeografica, (44), 071-88.

IICA. (2000). Instituto Interamericano de Cooperación para la AgriculturaDirección de Desarrollo Rural Sostenible. Jóvenes y nueva ruralidad. Protagonistas actuales y potenciales del cambio.Proyecto Género y Desarrollo Rural, IICA/ASDI

IICA. (1998). Instituto Interamericano de Cooperación para la Agricultura.La Juventud Rural como Actor del Desarrollo Sostenible. Dirección de Desarrollo Rural Sostenible.

Leff, E. (2000) La Complejidad Ambiental. Editorial Siglo XXI, México

Leff, E. (2002). Geopolítica de la Diversidad y el Desarrollo Sustentable. En C. y. (Coordinadores). La Guerra Infinita. Hegemonía y Terror Mundial (págs. 191 - 216). Buenos Aires. Clacso. 
Lozano, F. (2009). Comentario. Territorio, hegemonía y cultura. Las configuraciones de los Territorios Rurales en el siglo XXI (págs. 561 - 575). Bogotá: Editorial Pontificia Universidad Javeriana.

Martínez, L. G. (2006). La pedagogía crítica de Henry A. Giroux. Sinéctica, (29).

Ortega Y., (2012). La cultura ciudadana de redes sociales como un mecanismo de fortalecimiento de la democracia: un estudio de caso sobre la red juvenil territorio sur en Usme, 2009-2011. repository.javeriana.edu.co

Otero, A. (2003). Representaciones y participación juvenil: el caso de los jóvenes del movimiento de trabajadores desocupados de Lanús. Informe final del concurso: Movimientos sociales y nuevos conflictos en América Latina y el Caribe. Programa Regional de Becas CLACSO. Disponible en: www. CLACSO. org.

Pasín, Á. E. C. (2003). Una aproximación a la sociología de lo imaginario de Michel Maffesoli. Sociológica, 18(53), 101-119.

Pascagaza, G., \& Javier, E. (2010). Implementar la formación de líderes ambientales así como el Plan Educativo Institucional (PEI) con la ejecución del Seminario de Formación permanente Cátedra Enrique Pérez Arbeláez en el marco de la línea de acción innovación e investigación pedagógica del proyecto 317. Procesos de educación y cultura para la conservación y uso sostenible de la biodiversidad del Distrito Capital.

Pérez, M. (2004). La configuración territorial en Colombia: entre el conflicto, el desarrollo y el destierro. Cuadernos de Desarrollo Rural (51). p.62-90. En: http://www.javeriana.edu.co/ ier/recursos_user/documentos/revista51/61_90.pdf

Pinzón \& Sarmiento (2015). Una semana sin horario: estrategia para reorganizar la escuela por ciclos. intellectum.unisabana.edu.co.

Posner, B. Z., \&Kouzes, J. M. (1997). Ten lessons for leaders and leadership developers. Journal of Leadership\&OrganizationalStudies, 3(3), 3-10.

Proyecto Educativo Institucional (PEI).(2014). Institución Educativa Distrital Eduardo Umaña Mendoza. Secretaria de Educación del Distrito. Bogotá.

Rodríguez, E (2010). Políticas públicas de juventudes en América Latina. Avances concertados y desafíos a encarar en el marco del año internacional de la juventud. Bases para la construcción de respuestas integradas.

Ramírez, A. (2009). Análisis de los conflictos ambientales en interfases urbano-rurales. Revista nodo, 3(6).

Salovey, P. and Mayer, J.D. (1990), "Emotional intelligence”, Imagination, Cognition, and Personality, Vol. 9, pp. 185-211. 
Sastoque, V. A. (2015). Señor presidente no creo en vos; señor policía no temo de voz. Represión estatal y paramilitar y prácticas juveniles en los barrios Alameda, Brisas, Anita y Almendros. repository.urosario.edu.co.

Secretaria de Educación del Distrito. SED. Bogotá. (2012) (1). Plan sectorial de educación 2012 - 2016. Educación más Humana. Bogotá.

Secretaria de Educación del Distrito. SED. Bogotá. (2012) (2). Desarrollo socio afectivo. Reorganización curricular por ciclos. Herramienta pedagógica para padres y maestros. Disponible en: http://www.redacademica.edu.co/archivos/redacademica /colegios/politicas_educativas/ciclos/desarrollo_socioafectivo.pdf.

Secretaria de Educación del Distrito.(2014). Registro de información estadística SED Formulario oficial E-600. Colegio Eduardo Umaña Mendoza. Bogotá.

Sepúlveda, S., Castro \& Rojas. P., (998). Metodología para estimar el nivel de desarrollo sostenible en espacios territoriales. Instituto Interamericano de Cooperación para la Agricultura.

Sierra, C., Alonso, G., \& González, Y. (2009). Aproximación a un estado del arte de la didáctica en la educación ambiental. Doctoral dissertation, Tesis de Universidad de Antioquia Facultad de Ingeniería Especialización en Gestión Ambiental: Medellín.

Torres, A. (2015). Los conflictos ambientales en la cuenca del río Tunjuelo en Bogotá. En Torres A. \& Torres A. (Eds.), Acción colectiva. Gestión territorial y gobernanza democrática en Bogotá (pp. 225-263). Bogotá, Colombia: Universidad Piloto.

Tovar y Gálvez. (2012). Fundamentos para la formación de líderes ambientales comunitarios: consideraciones sociológicas, deontológicas, epistemológicas, pedagógicas y didácticas. Luna Azul, (34), 214-239.

Universidad Santo Tomas. (2014). Unidad de Investigación. Documento de línea de Investigación en Desarrollo, políticas públicas y planeación participativa. Facultad de Sociología. Bogotá Colombia.

Vidal, T y Pol, E. (2005). La apropiación del espacio: una propuesta teórica para comprender la vinculación entre las personas y los lugares. Universidad de Barcelona. (p. 1-17). Disponible en: http://www.raco.cat/index.php/anuariopsicologia/article /viewFile/61819/81003

Zárate A. \&Matviuk, S. (2012). Inteligencia emocional y prácticas de liderazgo en las organizaciones colombianas. Cuadernos de Administración (Universidad del Valle), 28(47), 91-104.

\section{Referencias Normativas}

De Bogotá, A. M. (2011). La política de infancia y adolescencia en Bogotá DC 2011-2021. Bogotá: Consejo Distrital de Política Social. 
De Colombia, C. P. (1991). Presidencia de la República. Bogotá.

Decreto 675 (2011) "Por medio del cual se adopta y reglamenta la Política Pública Distrital de Educación Ambiental" Diario Oficial 44.509 del 4 de agosto de 2011. Alcaldía Mayor de Bogotá.

Ley 99 (1993). Ministerio del Medio Ambiente (MMA). Colombia. Diario Oficial 41146 de diciembre 22 de 1993.

Ley 115 (1994). Ley General de Educación. Colombia. Ministerio de Educación Nacional (MEN) p.6-28. Disponible en: http://www.oei.es/quipu/colombia/Ley_115_1994.pdf

Ley 1549 (2012). Ministerio de Hacienda, Ministerio de Ambiente y Ministerio de Educación. República de Colombia 